\title{
A inclusão social e digital de pessoas com limitação visual e o uso das tecnologias de informação e de comunicação na produção de páginas para a Internet
}

Lizandra Brasil Estabel

Doutoranda em informática na educação - PGIE/UFRGS. Especialista em informática na educação - PGIE/UFRGS. Bacharel em biblioteconomia pela Fabico/UFRGS.

E-mail: estabel@cpovo.net

Eliane Lourdes da Silva Moro

Professora do Curso de Biblioteconomia da Fabico/UFRGS. Mestranda em educação da UFRGS - PPGEdu/UFRGS. Especialista em informática na educação - PGIE/UFRGS.

E-mail: eliane_moro@yahoo.com.br

Lucila Maria Costi Santarosa

Professora doutora do PPGEDU e do PGIE/UFRGS. Coordenadora nacional do Programa Nacional de Informática na Educação Especial (Proinesp) - UFRGS/MEC. Coordenadora de pesquisa do Núcleo de Informática na Educação Especial (NIEE/UFRGS).

E-mail: lucila.santarosa@ufrgs.br
Resumo

Este trabalho relata a atividade do acesso e do uso das tecnologias de informação e de comunicação (TICs), tendo como sujeito uma pessoa com necessidades educacionais especiais (PNEE) na produção de páginas para a Internet. $A$ atividade permitiu a observação das barreiras $e$ dificuldades enfrentadas e superadas, mediante o uso de ambiente de aprendizagem mediado por computador (AAMC). Foram utilizadas várias alternativas, formas de comunicação, tecnologias adequadas para a realização da atividade proposta, resultando em uma postura de compartilhamento no qual cada um tem muito para cooperar, para doar-se na busca de uma construção coletiva e na superação das limitações, sejam estas físicas e/ou tecnológicas. O artigo aponta que, com a educação e o uso das TICs, é possível promover a inclusão social e digital das PNEEs com limitação visual.

\section{Palavras-chave}

Informática na educação especial. Tecnologias de informação e de comunicação. Inclusão social e digital.

\section{Social and digital inclusion of people with visual impairment and the use of information and communication technologies in the creation of Internet pages}

\begin{abstract}
This work reports the activity of Information and Communication Technologies (ICTs) access and use having as subject a Person with Special Education Needs (PSENs) in the production of Internet pages. That activity has enabled the observation of obstacles and difficulties both faced and overcome through the use of an Environment of Learning Mediated by Computer (ELMC). A number of alternatives and communication modes as well as appropriate technologies have been used in order to work the proposed activity out. It has brought about a posture of sharing, through which each person has a lot to cooperate and to donate in a search for a collective construction and overcome limitations, whether physical or technological. The article points out that through education and ICT usage the social and digital inclusion of PSENs with visual impairment is possible.
\end{abstract}

Keywords

Informatics in special education. Information and communication technologies. Social and digital inclusion. 
A inclusão social e digital de pessoas com limitação visual e o uso das tecnologias de informação e de comunicação na produção de páginas para a Internet

\section{INTRODUÇÃO}

...onde a cegueira não seja vista como limitação ou empecilho, mas seja pensada como experiência criadora, como condição específica de um ser humano total (BELARMINO, 2005).

O acesso e a utilização da informática pelas pessoas com necessidades educacionais especiais (PNEEs) é uma das formas de inclusão digital e social, além de propiciar o acesso à informação de cidadãos excluídos. Em relação às PNEEs com limitação visual (pessoas com baixa-visão e cegos), a apropriação das tecnologias de informação e de comunicação (TICs) apresenta-se como uma forma de incluí-las digitalmente, comunicando-se e interagindo com os outros de forma que não se percebam as suas limitações. As tecnologias assistivas e adaptativas propiciam este processo de comunicação e interação, no qual o foco está na capacidade de compartilhar, aprender, interagir, construindo coletivamente em uma sociedade que muitas vezes as exclui.

Segundo dados da Organização Mundial de Saúde (OMS), existem aproximadamente 40 milhões de pessoas com necessidades especiais com limitação visual no mundo, das quais 75\% são provenientes de regiões de baixo poder socioeconômico. No Brasil, a incidência de PNEEs com limitação visual está na faixa de 1,0\% a 1,5\% da população, sendo de uma entre 3 mil crianças com cegueira, e de uma entre 500 crianças com baixa visão. A proporção é de $80 \%$ de pessoas com baixa visão e de $20 \%$ de pessoas totalmente cegas.

O censo escolar/2002, segundo dados do Instituto Nacional de Estudos e Pesquisas Educacionais Anísio Teixeira (Inep/MEC), registra 20.257 alunos com deficiência visual na educação básica do sistema educacional brasileiro. A análise desses dados reflete que muitas crianças, jovens e adultos com limitação visual encontram-se fora da escola.

Dados do Censo 2000 do Instituto Brasileiro de Geografia e Estatística (IBGE) apontam que 14,5\% da população brasileira é formada por PNEEs e, destas, 48\% são considerados indivíduos com limitação visual. Considera-se, de acordo com os dados apresentados, que metade dessa população possui limitação visual, tornando necessário e urgente a implantação de políticas governamentais de inclusão social, digital e educacional para acesso às TICs.

Diante do exposto, faz-se necessária a capacitação de professores, orientando-os para atender aos alunos PNEEs com limitação visual nas suas necessidades, propiciando-lhes um ambiente onde os alunos sejam agentes do seu processo de construção de conhecimento, interagindo com os outros. Com a modalidade de educação a distância mediada por computador, o Programa Nacional de Informática na Educação Especial (Proinesp) capacita os professores, alguns PNEEs, que trabalham com alunos com necessidades educacionais especiais para que se tornem capazes de orientá-los no processo colaborativo e cooperativo, em que é construído o conhecimento de forma coletiva, por meio da comunicação e da interação com o grupo.

Neste relato, pretende-se abordar o processo de construção de uma página pessoal para a Internet por uma professora/aluna do Proinesp com limitação visual e a superação das suas limitações, aceitando um desafio que, para ela, inicialmente era impossível, no decorrer de uma construção colaborativa e a interação mediada por computador.

\section{PNEEs COM LIMITAÇÃO VISUAL E A COLABORAÇÃO}

A interação entre PNEEs com limitação visual e as pessoas com visão normal deve se caracterizar como um processo estruturado no diálogo, na comunicação. Vygotski (1997, p.107) observa que "a fonte de compensação na cegueira não é o desenvolvimento do tato ou a maior sutileza do ouvido, mas a linguagem, quer dizer, a utilização da experiência social, da comunicação com os videntes". E afirma que "a palavra vence a cegueira".

O processo de comunicação entre videntes e cegos muitas vezes não se estabelece, em relação à escrita, quando não há o domínio do sistema Braille. Para um vidente, que nunca entrou em contato com este sistema, torna-se impossível fazer a leitura do texto. Para a pessoa com limitação visual, ao ter acesso a uma folha impressa, a tinta é o mesmo que uma folha em branco. Esta constatação serve para enfatizar a importância da linguagem como instrumento de mediação no processo de comunicação entre PNEEs com limitação visual e videntes. Somente na década de 90 , com o surgimento dos leitores de tela ou softwares de voz, esta situação foi modificada, à medida que o texto escrito é lido no momento em que o cego acessa o computador. A informática é um meio facilitador ao acesso das TICs. Dessa forma, as PNEEs com limitação visual sentir-se-ão incluídas digitalmente, minimizando as diferenças e propiciando a interação com o outro. 
Segundo Ferreyra (1998, p.30-39), os cinco sentidos - a audição, o tato, o olfato, o gosto e a visão - conectam o ser humano com o mundo. $\mathrm{O}$ autor afirma que a cultura dos meios eletrônicos proporcionou uma extensão que intensificou os sentidos do homem para promover uma nova oralidade, a ponto que "alguns cientistas da comunicação humana consideram que os meios eletrônicos estendam os nossos sentidos". A ausência de um dos sentidos, no caso, a visão, pode ser superada à medida que uma tecnologia adaptativa/assistiva possibilite a inserção da PNE com limitação visual ao ambiente digital.

Para Vygotski (1997, p.111), “as novas teorias não valorizam a cegueira em si nem o defeito, mas a força contida nela, as fontes de sua superação nos estímulos para o desenvolvimento do ser". Rego (1995, p. 71) afirma que o desenvolvimento pleno do ser humano depende do aprendizado que realiza em determinado grupo cultural, a partir da interação com os outros indivíduos da sua espécie.

A interação entre PNEEs com limitação visual e pessoas com as mesmas limitações ou não possibilita a superação das dificuldades a partir do compartilhamento com o outro. O indivíduo é responsável pelo seu aprendizado e pelo aprendizado do outro e dos outros. Para que a aprendizagem se realize, é necessário que haja um processo de troca, de construção colaborativa e cooperativa, mediado por instrumentos que possibilitem o acesso destas pessoas ao ambiente digital e o uso das TICs. Vygotski afirma que o sentido mais definido da mediação é o uso de mediadores para ampliar as possibilidades humanas na busca de atingir um fim, uma meta, para suprir determinadas necessidades, em um circuito de relações sociais. A aprendizagem colaborativa apoiada por computador deve ser uma estratégia educativa em que dois ou mais sujeitos constroem o seu conhecimento a partir da discussão, do diálogo, da reflexão, da tomada de decisão, tendo como instrumento mediador o computador. Para que este processo ocorra, professores e alunos devem estar dispostos a colaborar e construir conjuntamente.

Segundo Vygotski, existem dois níveis de desenvolvimento: o real e o proximal. O nível de desenvolvimento real representa as conquistas já consolidadas pela pessoa, o que aprendeu e domina sozinha; o desenvolvimento proximal, zona de desenvolvimento proximal (ZDP), constitui-se nas ações que a pessoa pode fazer com a ajuda de outras pessoas (colegas, professor, especialista).
Aquilo que é a zona de desenvolvimento proximal hoje será o nível de desenvolvimento real amanhã ou seja, aquilo que a criança pode fazer com assistência hoje ela será capaz de fazer sozinha amanhã. (VYGOTSKY, 1984, p.98).

É necessário que a pessoa com limitação visual supere as dificuldades e passe a ter maior autonomia. No entanto, somente com a colaboração do outro, ela conseguirá conquistar maior independência. Oportuniza-se a realização de novos relacionamentos, de se conhecerem melhor, descobrirem uns nos outros suas habilidades e a contribuição que cada um pode oferecer ao grupo em um processo de aprendizagem e construção de conhecimento.

A ZPD é coletiva (social), porque transcende os limites dos indivíduos ao se criar pela interação entre os indivíduos. Tanto crianças como adultos constroem o conhecimento conjuntamente, sendo todos os participantes aprendizes, aprendendo pela construção de representações compartilhadas pelo uso de instrumentos (PASSERINO; SANTAROSA, 2003).

Para que o grupo se fortaleça e consiga trabalhar de forma cooperativa e colaborativa, é necessário o estabelecimento do diálogo, da troca, da construção conjunta. Os integrantes do grupo devem ter objetivos comuns, todos devem contribuir uns com os outros. Cada integrante do grupo deve ser responsável pelo seu aprendizado e pelo aprendizado do outro. $\bigcirc$ grupo deve sempre retomar as atividades, fazendo uma avaliação do processo para que sejam retomados os pontos que devem ser aprimorados, e propiciar uma reflexão diante do processo de construção colaborativa. No entanto, este processo somente ocorrerá, se forem utilizadas ferramentas que possibilitem esta colaboração.

\section{O AMBIENTE DE APRENDIZAGEM MEDIADO POR COMPUTADOR E A APRENDIZAGEM COLABORATIVA}

A utilização de ambientes de aprendizagem mediados por computador (AAMCs) é a porta de entrada para a inclusão das pessoas no ambiente digital. Para a realização de cursos a distância, faz-se necessária a escolha criteriosa de um ambiente que possibilite a interação dos alunos, de forma que estes sejam agentes do seu processo de aprendizado, ficando o professor no papel de mediador, propiciando o exercício da cooperação e da colaboração na realização das atividades. 
A inclusão social e digital de pessoas com limitação visual e o uso das tecnologias de informação e de comunicação na produção de páginas para a Internet

O TelEduc, ambiente de aprendizagem mediado por computador, é um ambiente de fácil utilização e apresenta ferramentas de comunicação, como correio eletrônico, diário de bordo, fórum de discussão, mural, bate-papo, entre outras. Estas ferramentas possibilitam que o aluno tenha autonomia para a realização das atividades propostas e possa estabelecer uma relação de comunicação com os demais componentes do grupo, sem necessitar da intervenção do formador.

O Proinesp teve início em março de 2005, com carga horária de $120 \mathrm{~h}$, a participação de aproximadamente 310 professores de 155 escolas públicas e instituições nãogovernamentais contempladas com laboratórios de informática. O objetivo é capacitar os professores dessas instituições a trabalhar com a informática, de forma a incluir os alunos com necessidades educacionais especiais no ambiente digital, propiciando a inclusão e o exercício da cidadania.

Os professores foram divididos em 15 turmas, de aproximadamente 22 participantes em cada uma, provenientes de instituições localizadas nas diversas regiões do país. Em uma das turmas, participavam quatro professores com necessidades especiais com limitação visual.

Entre as atividades propostas semanalmente, no Módulo Usos Pedagógicos da Internet, estava a construção de uma página em HTML individualmente ou em grupo. A proposta estabelecia a utilização do software Frontpage para a construção da página e os recursos deste software agregan-do texto, imagem, som, entre outros recursos. A página construída previa a publicação no ambiente TelEduc, com acesso restrito aos participantes do curso, e depois seria disponibilizada na Internet para livre acesso.

No caso das PNEEs com limitação visual, deve haver cuidado com relação à acessibilidade das páginas. Os sites podem apresentar poucos problemas de acessibilidade, se forem construídos em HTML. Deve haver cuidado especial com a utilização de Flash e Applets Java, que tornam os sites inacessíveis, a utilização de frames e tabelas que dificultam a navegação; as figuras que devem incluir o "alternate name", o atributo "alt" em HTML, com a descrição, para que as PNEEs com limitação visual saibam do que se trata e, quando a figura for um link, ser acompanhada da função que ela simboliza. Ao término da construção de uma página, é interessante verificar se ela atende aos critérios de acessibilidade, submetendo-a a um validador como Bobby (http:// www.cast.org/bobby), o W3C (http://validador.w3.org), o
TAW (www.tawdis.net) ou o Da Silva (http:// www.acessobrasil.org.br/), o primeiro avaliador de acessibilidade em língua portuguesa.

Uma das participantes com limitação visual, denominada M.S. (para preservar a sua identificação), sentiu-se desafiada para a realização da atividade de construção da página pessoal na Internet, tendo em vista que as ferramentas disponíveis para a execução não favoreciam a adaptabilidade e a acessibilidade de PNEEs com limitação visual. Diante do desafio, a vontade da superação foi maior do que o desânimo e o desencorajamento, para efetuar a atividade proposta do curso.

\section{O DESAFIO DA CONSTRUÇÃO DA PÁGINA PESSOAL}

Ao solicitar para os professores/alunos a construção da página em HTML, imediatamente a professora/aluna M.S. enviou um e-mail com o seguinte comentário:

Dia: 23/04 - 15h10min

"Eu [não] sei de linguagem HTML [...] esse frontpage [não] é acessível pra cegos. Vou tentar copiar aqui um index.html de um amigo e criar alguma tentativa de página na intervox, que é onde já tenho conta de FTP. [...]Verei o que consigo.”

Diante do exposto, talvez a reação da formadora (professora responsável pela turma) fosse a de determinar a realização de uma outra atividade para compensar aquela determinada para o grupo; ou de liberá-la da realização desta atividade, justificando a não-acessibilidade das ferramentas disponíveis. No entanto, por acreditar que, apesar das limitações em relação à acessibilidade, é possível buscar outras alternativas, a formadora desafiou M.S.:

Resposta - Dia: 23/04 - 15h17min

Calma, minha querida. Vamos por partes.... Tens mais uma semana para fazer. O texto deve ser digitado normalmente, como no Word. A maior dificuldade são os links e as figuras. Queres tentar, podemos fazer juntas a distância. Escreves o texto, e vou te orientando em relação às imagens e etc... Te aguardo.

A resposta foi imediata:

Dia: 23/04 - às 16h01min

[...] Vou aceitar a tua ajuda, deixa eu tentar ver o que consigo vendo o index.html da página de um amigo. 
A resposta da aluna e a decisão de aceitar o desafio estabeleceram uma relação de cumplicidade entre as duas e, ao mesmo tempo, de crença na possibilidade de uma construção conjunta. Faz-se necessário estabelecer esta relação, na qual o que é ZDP hoje será o nível de desenvolvimento real amanhã, pois, por meio da troca com o outro que possui determinado conhecimento, este saber será compartilhado, em uma construção conjunta, colaborativa e cooperativa.

Vygotsky afirma que o bom ensino é o que se adianta ao desenvolvimento, ou seja, que se dirige às funções psicológicas que estão em vias de se completarem. Esta dimensão prospectiva do desenvolvimento psicológico é de grande importância para a educação, pois permite a compreensão de processos de desenvolvimento que, embora presentes no indivíduo, necessitam da intervenção, da colaboração de parceiros mais experientes da cultura para se consolidarem e, como conseqüência, ajuda a definir o campo e as possibilidades da atuação pedagógica (REGO, 1995, p.107).

No mesmo dia, ao ser desafiada para a construção da página, M.S. escreveu:

\section{Dia: 23/04 - às 18h55min}

[...] já estou no terceiro capítulo de um livro que tenho sobre HTML. Sempre costumo falar que pra nós cegos os caminhos são mais tortuosos, mais cheios de atalhos. É como se a gente tivesse que fazer as coisas sempre de forma manual, sabendo todos os meandros, nada que um clique rápido resolva. Poderia te enviar o texto e ficar livre disso, mas não saberia como é o processo.

A relação de construção e de colaboração foi estabelecida. Pode-se observar que M.S. assumiu o papel ativo de construção do seu conhecimento à medida que deixou a postura de apenas cumprir uma tarefa, enviando um texto e ficando "livre" da atividade, e se prontificou a colaborar e receber colaboração. E ela continua:

Estou na fase de testes. Estou sozinha em casa e não tem ninguém que me diga se minha foto está aparecendo no link. Vou te dar o endereço onde vais ver meu primeiro teste, sem enfeites. Só um textinho e um link com a minha foto. Por favor, acesse e me contes se ela já aparece pra ver se estou no caminho certo.

Nesta situação, ainda não é possível utilizar uma tecnologia assistiva/adaptativa que atenda a essa necessidade, embora não seja um impedimento para a realização das atividades, quando se acredita que é possível construir com o outro em um estabelecimento de colaboração. Se a tecnologia é a extensão da mão do homem, as relações interpessoais são o que incentivam o ser humano a superar as suas limitações. Neste caso, a formadora "empresta" o seu olhar para atender a esta necessidade, consciente de que a professora/aluna é capaz e interferindo mais diretamente neste processo somente quando não é possível realizar sozinha determinada ação. Existe uma relação de cooperação, mas em nenhum momento a formadora intercedeu pela aluna. É uma construção conjunta que visa à autonomia de quem, em algum momento, sente-se limitado. A formadora tem o papel de mediadora neste processo.

No decorrer da atividade, M.S. enfrenta um dos obstáculos que é o uso do mouse pelos cegos, instrumento que não é utilizado por causa da dificuldade de organização espacial e localização na tela. Os cegos utilizam o teclado, e este não precisa ser em Braille, pois, em razão de uma marcação nas letras $\mathbf{f}$ e $\mathbf{j}$, eles posicionam as mãos e, fazendo uso de atalhos, conseguem utilizar a maioria dos recursos disponíveis no computador.

[...]Vocês são do mouse, e eu sou do teclado e dos comandos! Estou fazendo uma lista de comandos em HTML, vou imprimir e fica mais fácil. Para me contar o resultado, acesses: intervox...

Ao acessar a primeira tentativa de criação de página em HTML de M.S., o título inicial era "Meus primeiros passos". Havia uma saudação para as pessoas que acessassem a sua página e um link para a sua foto. Este link estava funcionando corretamente. Também apresentava um link para o seu e-mail e uma mensagem sonora de boasvindas, mas que estava demorando muito tempo para iniciar.

Após alguns comentários sobre a página, no dia seguinte, M.S. enviou esta resposta:

Dia:24/04 - às 9h25min

[...] quero sim que me mandes a forma de entrar na página com um som automático. Me digas em que lugar coloco esse comando. Já que é página de cego, prefiro lidar com sons. Vou configurar ainda os tamanhos das fontes, andei lendo sobre HTML ontem um tempão. Pena que eu nunca vá saber como fica esteticamente, mas fazer o quê?

Mandes tudo que puderes sobre HTML, esses comandos são um saco [difíceis], mas a gente vai colando! 
A inclusão social e digital de pessoas com limitação visual e o uso das tecnologias de informação e de comunicação na produção de páginas para a Internet

Nesta mensagem, M.S. revela uma das características apresentadas na maioria dos sites construídos por e para cegos, o uso de arquivos de som. Em geral, as páginas possuem recursos sonoros. No caso desta aluna, a sua página, além de apresentar uma saudação ao acessá-la, apresenta links com músicas de sua interpretação, pois ela também é cantora e possui programas, de sua autoria, apresentados em uma rádio virtual. Outra questão neste e-mail é em relação à estética da página. Por sua limitação visual, M.S. observa que nunca poderá saber como ficou esteticamente, mas confia na opinião de quem a está auxiliando. Também há preocupação em relação à forma como está sendo construída a página, para que as pessoas que irão acessá-la e que possuem visão normal possam ter acesso a uma página com um leiaute adequado, em função do tamanho da fonte e das cores utilizadas.

No primeiro contato, surgiu a reclamação sobre o uso do FrontPage. Em determinado momento, M.S. foi questionada sobre qual software estaria utilizando para a construção das suas páginas:

\section{Dia: 24/04 - às $14 \mathrm{~h} 37 \mathrm{~min}$}

[...] vou construindo os arquivos HTML no edivox mesmo, mas poderia usar o bloco de notas. É que de qualquer maneira já estou lá no f t p vox e daí fico por lá mesmo, lendo os textos de HTML e tentando aplicar os comandos.

O edivox é um dos programas do sistema operacional Dosvox, que é um programa sonoro, com um sintetizador de voz que possui mais de 70 programas, como cartavox (correio eletrônico), papovox (bate-papo), webvox (para navegar na Web), intervox (criação de homepages), calcuvox (calculadora), entre outros. Este software auxilia as PNEEs com limitação visual na edição de textos.

M.S. passou a explorar a sua página e solicitar auxílio para incrementar novos comandos. Em determinado momento, ela solicita que a oriente a colocar um link que remeta para o início da página ou para a página inicial.

A limitação de M.S. para a realização da atividade evidenciou um ritmo diferenciado dos demais colegas, que foi suprido pela possibilidade do compartilhamento com o mediador, propiciando a ampliação da sua capacidade de realizar a atividade.

Os diferentes ritmos, comportamentos, experiências, trajetórias, contextos familiares, valores e níveis de conhecimento de cada sujeito imprimem ao cotidiano escolar a possibilidade de troca de repertórios, de visão de mundo, de confrontos, ajuda mútua e conseqüente ampliação das capacidades individuais (REGO, 1995, p. 110)

Apesar de nunca ter construído uma página em HTML, M.S. faz uso das tecnologias e da Internet há longo tempo. Esta experiência possibilita que ela faça avaliações em relação ao seu site, comparando com recursos utilizados em outras páginas. Pode-se fazer esta afirmação diante da solicitação a seguir e de outras feitas anteriormente:

Dia: 24/04 - às 17h23min

[...]Talvez falte eu saber alguns comandos, tipo pra colocar meu nome no início... Vou pensar no título! Fui fazendo tudo no entusiasmo! [...] Agora estou empolgada! Vou continuar e sempre de olho nas tuas dicas!

Ao ler esta mensagem, pode-se fazer um comparativo dela com a primeira mensagem recebida. Em um primeiro momento, poder-se-ia acreditar que não seria possível a construção de páginas pela aluna. No entanto, ela foi desafiada a tentar, aceitou o desafio e conseguiu realizar a atividade.

Esse processo foi possível porque houve a vontade intrínseca e o desejo de realizar a atividade proposta. O processo intrapsicológico motivou a realização da ação, tornando o sujeito inclú́do no grupo.

Para que exista a apropriação, é preciso que exista a internalização, que implica a transformação dos processos externos (concretizado nas atividades entre pessoas), em um processo intrapsicológico (em que a atividade é reconstruída internamente). O longo caminho do desenvolvimento humano segue, portanto, a direção do social para o individual (REGO, 1995, p.109).

Ao longo de todo o processo, não faltaram palavras de incentivo e a crença de que ela poderia conseguir se fosse auxiliada e incentivada a continuar. "Agora estou empolgada! Vou continuar e sempre de olho nas tuas dicas!” (M.S.). Nesta mensagem, pode-se observar que há motivação interna e relação de confiança, de troca entre a formadora e a aluna. A formadora faz a mediação no processo, orientando-a, auxiliando-a na sua aprendizagem. A aluna demonstra este entusiasmo, ao convidar outras pessoas e colegas para acessar a sua página: 
Dia 25/05 - às 24h26min

[...] Uma amiga me disse que eu colocasse uma legenda sobre mim ao lado da foto, mas não sei se precisa.

Nesta mensagem, M.S. ressalta uma das dificuldades em relação à acessibilidade. Se as imagens não possuírem uma descrição, elas perdem a importância quando acessadas por uma pessoa com limitação visual. Ao navegar nas páginas com um leitor de telas, este irá falar a palavra gráfico, somente. Faz-se necessário utilizar o atributo "alt", descrevendo o que aparece na imagem.

Resposta: Dia 25/05 - às 10h34min

[...] Em relação à foto, poderias fazer uma descrição. Desta forma, tua página estaria seguindo as normas de acessibilidade. A descrição serve para que, quando o leitor de telas passar pela imagem, ele faça a descrição do que aparece na tela. Caso contrário, o leitor dirá: foto e tantos kb. Agora, vamos aprimorando.... $\bigcirc$ principal tu fizeste.

A imagem que M.S. colocou em sua página é uma foto pessoal, sentada em um banco de praça. Esta descrição foi colocada em sua página. Uma das observações que ela fez foi em relação aos materiais publicados em seu site. Preferiu colocar textos e programas, da rádio virtual, de sua autoria e músicas interpretadas por ela mesma. A página criada por M.S. possui a sua autoridade e a sua autoria, construídas por meio do compartilhamento e da superação da limitação das ferramentas tecnológicas.

Ao final desta primeira construção, pois toda página está sempre em construção e nunca acabada, M.S. optou por colocar o título (O ESPECIAL DA EDUCAÇÃO), pois, segundo suas palavras, o especial está em acreditar que é possível superar as limitações a partir da construção com os outros e de saber que se pode superar as limitações quando se acredita que é possível.

A última mensagem enviada por ela, ao longo destes três dias de muita interação, foi a seguinte:

\section{6/04 - às 24h16min}

[...] já fiz as alterações, chamei meu filho pra ver! Ele adorou! Quer que eu faça uma pra ele! Imagina! O trabalho que dá! Eles sabem que passaram o fim de semana sem poder vir ao micro! Beijos e obrigada!

Após alguns dias, M.S. enviou um e-mail informando que está trabalhando a construção de páginas com seus alunos com limitação visual.
Na auto-avaliação sobre a construção da página, M.S. fez os seguintes comentários:

Aprendi a construir juntos, conjugar o coletivo, pois, sem a ajuda da formadora, seria impossível essa construção. Aprendi a valorizar a disponibilidade incondicional de uma pessoa pronta a nos ajudar, parecendo um plantão SOS! [...] Contei com uma disposição interna, uma motivação, porque aprendi o que desejava aprender, um tirocínio psicofísico como diz o Gramsci, cansaço e muita perseverança. Essa foi a construção mais apressada pelas próprias exigências da atividade do curso, exigências essas que não me fizeram nenhum mal. Vou aperfeiçoar a página, cadastrá-la, torná-la cada vez mais acessível. Aprender é um verbo conjugado ad infinitum! (M.S.)

Aprender é realmente um verbo conjugado infinitamente, pois propicia a todos os envolvidos no processo o crescimento, uma mudança no seu estado inicial. Em determinado momento, não existia mais formadora/ professora e aluna. Ambas compartilhavam o desejo de construir, de aprender. Era uma situação nova, na qual foi necessário buscar várias alternativas, formas de comunicação, tecnologias adequadas e, acima de tudo, colocar-se em uma postura de compartilhamento em que cada um tem muito para cooperar, para doar-se na busca de uma construção coletiva e na superação das limitações, sejam estas físicas e/ou tecnológicas.

\section{CONSIDERAÇÕES FINAIS}

Desde o primeiro momento, quando foi proposta a atividade de construção da página em HTML, tinha-se consciência do desafio que seria esta tarefa por causa da dificuldade de uso de algumas tecnologias, da distância física, sendo esta construção mediada por computador, e das limitações apresentadas pela ausência de visão.

No entanto, todas estas dificuldades ou empecilhos poderiam ser superados, se houvesse acima de tudo a vontade de construir, de superar, de aceitar os desafios. Vygotski (1988, p.34), em seus estudos sobre PNEEs, sempre "interessou-se mais por suas forças do que por suas deficiências". Acredita-se que, por meio do compartilhamento, da troca, da cooperação, é possível superar as limitações. A troca de papéis entre a formadora e a aluna, em muitos casos, quando cada uma auxiliava a outra, sugerindo, interagindo, informando, possibilitou esta construção. Seria muito mais fácil, se tivesse sido proposta outra atividade. Diante das dificuldades e da primeira reação de M.S., a aluna poderia ter copiado uma 
A inclusão social e digital de pessoas com limitação visual e o uso das tecnologias de informação e de comunicação na produção de páginas para a Internet

página pronta e apenas ter alterado alguns dados, poderiam ter sido utilizadas várias "desculpas" para a nãorealização desta atividade, mas ficaram presentes o desafio e a certeza de que as dificuldades e limitações são superadas no compartilhamento com o outro. Faz-se necessário desequilibrar para equilibrar, sair da posição de passividade e assumir o papel de agente do seu aprendizado.

Hoje, M.S. sente-se capaz de construir outras páginas, de atualizar a sua em processo de construção permanente e de ensinar os seus alunos, PNEEs com limitação visual, a realizar esta construção.

Este relato poderia ter ficado apenas na primeira mensagem, mas isto não aconteceu, pois ainda existem pessoas que acreditam que é possível ir muito além, que é possível superar as barreiras, pois as limitações estão dentro das pessoas e é preciso muita coragem e apoio dos outros para superá-las.

No Brasil, conforme dados estatísticos apresentados neste artigo, existem 20.257 alunos com limitação visual na educação básica do sistema educacional brasileiro. Faz-se necessária a capacitação de professores para melhor atender a estes alunos, mas com uma proposta de construção colaborativa, propiciando, por meio da construção com o outro, autonomia a estes alunos. As dificuldades a serem superadas são muitas: de acesso à informação, aos materiais especiais adequados que atendam às suas necessidades, ao uso de tecnologias assistivas e adaptativas, mas principalmente de uma postura do professor de mediador deste processo, propiciando ao aluno um papel ativo na construção de seu conhecimento. A busca da superação das limitações está dentro do ser humano, basta acreditar e construir.

Não são poucos os exemplos de superação, como apresentados neste artigo, mas é preciso ter um outro olhar, acreditando-se que deficiente é a sociedade que exclui ou que não possibilita a inclusão destas PNEEs em uma sociedade de tantas diferenças.

Artigo submetido em 06/05/2005 e aceito em 10/07/2006.

\section{REFERÊNCIAS}

BELARMinO, Joana. Entrelinhas. Disponível em: <http:// intervox.nce.ufrj.br/ joana/textos/entrelinhas_jan-jun2004.doc. $>$. Acesso em: 28 mar. 2005.

FERREYRA, Erasmo Norberto. A linguagem oral na educação de adultos. Porto Alegre: Artes Médicas, 1998.

PASSERINO, L. M.; SANTAROSA, L. M. C. Vygotsky e os ambientes telemáticos. Disponível em: <http://libra.niee.ufrgs.br/ proinesp/ amb_dig/index.html>. Acesso em: 2 abr. 2003.

REGO, T. C. Vygotsky: uma perspectiva histórico cultural na educação. Petrópolis: Vozes, 1995.

SANTAROSA, L. M. C. Cooperação na web entre PNEE: construindo conhecimento no núcleo de informática na educação especial da UFRGS. In: CONGRESSO IBERO-AMERICANO DE INFORMÁTICA NA EDUCAÇÃO ESPECIAL, 3., 2002, Fortaleza. Anais... Fortaleza: SEESP/MEC, 2002. p. 64-79.

VYGOSTKY, L. S. A formação social da mente. São Paulo: Martins Fontes, 1984.

Visor, 1997. v. 5

Obras escogidas: fundamentos de defectologia. Madrid:

VIGOTSKII, L. S.; LURIA, A. R.; LEONTIEV, A. N. Linguagem, desenvolvimento e aprendizagem. 2. ed. São Paulo: Ícone, 1988. 